\title{
Lost in translation? Multi-metric macrobenthos indicators and bottom trawling
}

\author{
Gislason, Henrik; Bastardie, Francois; Dinesen, Grete E.; Egekvist, Josefine; Eigaard, Ole Ritzau
}

Published in:

Ecological Indicators

Link to article, DOI:

10.1016/j.ecolind.2017.07.004

Publication date:

2017

Document Version

Peer reviewed version

Link back to DTU Orbit

Citation $(A P A)$ :

Gislason, H., Bastardie, F., Dinesen, G. E., Egekvist, J., \& Eigaard, O. R. (2017). Lost in translation? Multi-metric macrobenthos indicators and bottom trawling. Ecological Indicators, 82, 260-270.

https://doi.org/10.1016/j.ecolind.2017.07.004

\section{General rights}

Copyright and moral rights for the publications made accessible in the public portal are retained by the authors and/or other copyright owners and it is a condition of accessing publications that users recognise and abide by the legal requirements associated with these rights.

- Users may download and print one copy of any publication from the public portal for the purpose of private study or research.

- You may not further distribute the material or use it for any profit-making activity or commercial gain

- You may freely distribute the URL identifying the publication in the public portal 


\section{Lost in translation? Multi-metric macrobenthos indicators and bottom} trawling.

Henrik Gislason ${ }^{\mathrm{a}, \mathrm{b}}$, Francois Bastardie ${ }^{\mathrm{b}}$, Grete E. Dinesen ${ }^{\mathrm{b}}$, Josefine Egekvist and Ole Ritzau Eigaard ${ }^{b}$

a)Corresponding author, e-mail: hg@aqua.dtu.dk

b)Technical University of Denmark, National Institute of Aquatic Resources, Kemitorvet bygn. 2001, DK2000 Kongens Lyngby, Denmark

\section{Abstract}

The member states of the European Union use multi-metric macrobenthos indicators to monitor the ecological status of their marine waters in relation to the Water Framework and Marine Strategy Framework Directives. The indicators translate the general descriptors of ecological quality in the directives into a single value of ecological status by combining indices of species diversity, species sensitivity and density. Studies and inter-calibration exercises have shown that the indicators respond to chemical pollution and organic enrichment, but little is known about their response to bottom trawling. We use linear mixed effects models to analyze how bottom trawling intensity affects the indicators used in the Danish (Danish Quality Index, DKI) and Swedish (Benthic Quality Index, BQI) environmental monitoring programs in the Kattegat, the sea area between Sweden and Denmark. Using year and station as random variables and trawling intensity, habitat type, salinity and depth as fixed variables we find a significant negative relationship between the BQI indicator and bottom trawling , while the DKI is related significantly to salinity, but not to trawling intensity. Among the indicator components, the species diversity and sensitivity indices used in the DKI are not significantly linked to trawling, and trawling only affects the BQI when species sensitivities are derived from rarefied samples. Because the number of species recorded per sample (species density) is limited by the number of individuals per sample (density), we expect species density and density to be positively correlated. This correlation was confirmed by a simulation model and by statistical analysis of the bottom samples in which log species density was highly significantly related to $\log$ density $(\mathrm{r}=0.75, \mathrm{df}=144, p<0.001)$. Without accounting for the effect of density on species density, indicators based on species density will be affected by temporal and spatial variations in density linked e.g. to variable recruitment 
33 success. When this variation is accounted for by random year and station effects we find log 34 trawling intensity to explain more of the variation in log density than in the indicators 35 currently used to monitor Good Ecological and Environmental Status in the Kattegat.

36 Disregarding random effects and the relationship between density and species density, the 37 impacts of bottom trawling are likely to be lost in the translation of ecological quality into 38 macrobenthos indicators.

39 Keywords: macrobenthos indicators, bottom trawling, density, species richness, Water 40 Framework Directive, Marine Strategy Framework Directive 


\section{Introduction}

Quantification of the ecological status of marine soft-bottom macrobenthos has become increasingly important in Europe after the implementation of the European Water Framework Directive (WFD; 2000/60/EC) and the European Marine Strategy Framework Directive (MSFD; 2008/56/EC). Both directives contain descriptors of ecological quality and require the status of marine macrobenthos to be assessed and expressed relative to a situation where anthropogenic impacts are either negligible or at a sustainable level (Van Hoey et al. 2010, Borja et al. 2013). However, translating the qualitative descriptors in the directives into quantitative measurable ecological and environmental properties is an ongoing challenge (Van Hoey et al. 2010). So far the translation has relied heavily on the use of ecological quality indicators which have been used to express the current ecological and environmental status in relation to the desired (Rice et al. 2012, Birk et al. 2012). The main purpose of these indicators is to link a specific anthropogenic pressure to a change in ecological quality extracted from a multivariate response (Hiddink et al. 2006, Muntadas et al. 2016, Rijnsdorp et al. 2016). The link between pressure and response is important because the likelihood that managers will act to reduce or remove ecologically adverse pressures depends on the quality and strength of the scientific evidence that action will result in the outcome intended. Without a scientifically well documented causal relation between a particular pressure and ecological status, managers may be less likely to regulate ecologically adverse pressures, in particular if these pressures are generated by human activities that are economically, politically or socially important. Examining how well indicators link pressure to state is therefore important.

The member states of the European Union have been granted considerable flexibility regarding the implementation of the WFD in their national marine waters and, as a result, many have selected their own indicator to quantify the status of their soft-bottom macrobenthic invertebrate fauna (Quintino et al. 2006, Borja \& Dauer 2008, Pinto et al. 2009, Josefson et al. 2009, Birk et al. 2012, Borja et al. 2015). Most of these indicators address the normative definitions and terms of the WFD and therefore include estimators of 'the level of diversity and abundance of invertebrate taxa' and the proportion of 'disturbance-sensitive taxa' (Vincent et al. 2002, Borja et al. 2004). In practice, this means that they combine a diversity index with an expression of the number of individuals or species present in each 
sample and a formula reflecting the observed relative occurrence or abundance of disturbance-sensitive macrobenthic taxa. To assess the relative occurrence of disturbancesensitive taxa the majority of the member states use the AZTIs Marine Biotic Index (AMBI) (Borja et al. 2000), and a few use the sensitivity metric in the Benthic Quality Index (BQI) (Rosenberg et al. 2004), or other metrics. To reflect 'the level of diversity' Shannon's diversity index $\left(\mathrm{H}^{\prime}\right)$ (Shannon \& Weaver 1963) is often used, and to reflect 'abundance of invertebrate taxa', either the number of species recorded or a combination of species recorded and individual density is most often used (Borja et al. 2009). Hence, sensitivity as defined by AMBI or by the BQI, diversity as reflected by $\mathrm{H}^{\prime}$, and some function of the number of species recorded or density are the most common metrics incorporated in the indicators.

Most of the development, testing and inter-calibration of the national macrobenthos indicators have focused on their response to eutrophication, organic enrichment and chemical pollution (Borja et al. 2007, Borja et al. 2015), and comparatively little work has been spent on examining their response to bottom trawling and seabed abrasion. This is problematic because fisheries generated abrasion exerts a significant pressure on soft-bottom macrobenthic communities in many areas (Kaiser et al. 2006, Collie et al. 2016, Eigaard et al. 2016, 2017). Furthermore, the response of the benthic fauna to mechanical abrasion may very well differ from its response to eutrophication, organic enrichment and chemical pollution. According to the widely accepted 'Pearson and Rosenberg model', organic enrichment will initially increase the growth, density and species richness of the macrobenthos (Pearson \& Rosenberg 1978, Gray et al. 2002). A further increase in organic enrichment will increase the oxygen uptake of the seabed eventually resulting in hypoxia or anoxia and a decline in species richness due to a reduction in density or disappearance of sensitive species unable to thrive at low oxygen concentrations. In contrast, mobile bottom-contacting fishing gears are known to kill or damage organisms that are sensitive to mechanical abrasion (Kaiser et al. 2006, Clark et al. 2016, Collie et al. 2016, Neumann et al. 2016). A single passage of a bottom trawl will typically kill $20-50 \%$ of the benthic invertebrates in the path of the gear (Collie et al. 2016), but the response is variable and depends on the type of habitat (e.g. substrate), the level of natural disturbance (e.g. hydrographic regime), the species composition of the benthic community, and the footprint of the gear in use (Kaiser et al. 2006, van Denderen et al. 2014, 2015, Eigaard et al. 2016, 2017). Where the longer term response of soft-bottom marine 
macrobenthos to organic enrichment is expected to be a uni- or bi-modal change in benthos biomass, density and species richness, the response to an increase in bottom trawling seems more likely to be a monotonic decline in the biomass and density of sensitive organisms that are sampled by bottom corers and grabs (Queirós et al. 2006, Hinz et al. 2009).

There is, however, a fundamental, but frequently neglected problem that can compromise the assessment of biodiversity with bottom corers and grabs. A single sample represents a fixed sampling area and provides an estimate of species density (the number of species per sampling area), and not species richness (the total number of species present in the habitat sampled). Estimates of species density are often highly correlated with the number of individuals recorded in the samples. This correlation is known to complicate analyses of changes in species density (Gotelli \& Collwell 2010, Chase \& Knight 2013). For instance, if a sample only contains ten individuals, no more than ten species can be identified, irrespective of the total number of species that are actually present in the habitat sampled. Hence, when density changes at a particular location due to e.g. natural fluctuations in recruitment success or increased mortality caused by bottom trawling, the number of individuals contained in each sample will change, and so will the number of species recorded. A change in the number of species recorded can thus be produced both by a change in the number of species occurring at the location and by a change in the density of individuals affecting how likely it is that the species are represented in the samples. Most macrobenthic indicators use species density to quantify ecological quality and may therefore respond to changes in individual density and distribution as well as to the number of species present.

The purpose of this study is therefore twofold: To investigate the response of the current macrobenthos indicators to bottom trawling; and to examine how the link between species density and individual density may affect the indicators. To this end we analyze a dataset from the Danish macrobenthos monitoring program in the Kattegat between Denmark and Sweden. We focus on the response of the multi-metric DKI and BQI indicators used to monitor macrobenthos quality by the two countries in relation to the Water Framework Directive. Both indicators contain similar elements as the majority of macrobenthos indicators used by other EU member states. Using mixed effects models and estimates of trawling intensity around the benthos sampling stations we investigate how the indicators and their components respond to trawling intensity using salinity, habitat type, and depth as co- 
variates and station and year as random effects. Finally, we discuss how to evaluate the ecological status of macrobenthic communities in relation to bottom trawling and other anthropogenic pressures.

\section{Material and Methods}

\subsection{Study area}

The Kattegat is situated between Sweden and Denmark and has a total area of $\sim 22000 \mathrm{~km}^{2}$ (Figure 1). Most of the western part is relatively shallow and sandy with depths between 10 and $20 \mathrm{~m}$, but the northern and eastern parts comprise a complex postglacial seascape with deep muddy canyons down to $150 \mathrm{~m}$ in between shallower mounts of mixed sediments and reefs formed by leaking gases (Al'Hamdani et al. 2007). The Kattegat connects the saline North Sea (salinity $>30 \mathrm{ppm}$ ) with the more brackish Baltic Sea $(<20 \mathrm{ppm})$ and exhibits a strong vertical stratification as well as a horizontal salinity gradient where salinity below the halocline declines from $34 \mathrm{ppm}$ in the north to $28 \mathrm{ppm}$ in the south. An intensive bottom trawl fishery for Norway lobster (Nephrops norvegicus) impacts the deeper ( $\geq 16 \mathrm{~m}$ ) soft-bottom macrobenthic communities (Pommer et al. 2016). In the more shallow sandy areas, a now much reduced bottom trawl fishery for plaice (Pleuronectes platessa) and cod (Gadus morhua) takes place (Svedäng et al. 2010, Cardinale et al. 2010). The Kattegat has been subject to eutrophication and suffered from hypoxic and anoxic events in the 1980's, but since then the amount of nutrients from land has been reduced and the frequency of hypoxic events has declined (Riemann et al. 2016).

\subsection{Benthos samples}

Benthos was sampled annually on 22 fixed stations using a Haps corer covering an area of $0.0143 \mathrm{~m}^{2}$ (Kanneworff \& Nicolaisen 1973). At each station five replicate Haps samples were collected in April or May in the years 2005-2008, 2010, 2011 and 2013 (Figure 1). Each Haps sample was carefully flushed through a $1 \mathrm{~mm}$ mesh sieve to extract the animals, which were preserved in a $96 \%$ ethanol solution (Josefson and Hansen 2014). In the laboratory, all individuals were sorted and identified to the lowest possible taxon, preferably to the species level, and the number of individuals of each species or taxon was counted. To reduce the 
variance the five Haps samples from each station were combined prior to the calculation of the DKI and BQI indices. At each station estimates of the average near bottom salinity, depth and sediment type at EUNIS (European Nature Information System) habitat level 3 were available.

\subsection{Trawling intensity}

The area swept by trawling was estimated within a circle with a radius of $2 \mathrm{~km}$ centered at each benthos station. Recruitment of most benthic species in the area takes place from early spring until late autumn and many of the organisms present in the samples in late April or early May will be surviving recruits from the previous year. At each station trawling intensity was therefore cumulated over the period from May in the preceding year to April in the year where the bottom samples had been collected. The area swept was estimated by combining data from the Danish Vessel Monitoring System (VMS) with logbook data and estimates of the towing speed and dimensions of the trawl gears that had been used. Before 2012, the VMS was only mandatory for vessels longer than $15 \mathrm{~m}$, but although some smaller bottom trawlers fish in the Kattegat, vessels $\geq 15 \mathrm{~m}$ constitute by far the largest part of the bottom trawlers (Danish AgriFish Agency 2016). Vessel speed was used to separate actively fishing vessels from steaming and idle vessels. To calculate the footprint for each logbook-registered fishing trip, we used the relationships between gear dimensions and vessel size (e.g. trawl door spread and vessel engine power (kW)) from Eigaard et al. (2016) for different gear types, vessel groups and target species. Combined with vessel tracks based on the VMS positions and the interpolation method of Hintzen et al. (2010) these data were used to calculate trawling intensity, defined as the ratio of the annual area swept to the size of the circular area surrounding each station. The average trawling intensities ranged from 0 times per year to 73 times per year at the stations in the central part of Kattegat (Figure 1).

\subsection{Macrobenthos Quality Indicators}

The current version of the Danish Quality Indicator (DKI) is described in Henriksen et al. (2014). It combines the AMBI index of Borja (2000), where species or taxa are classified according to their sensitivity to organic enrichment and pollution, the number of individuals $\mathrm{N}$, and Shannons diversity index $\mathrm{H}^{\prime}$, calculated using $\log _{2}$. The AMBI and Shannon indices 
were both standardized by means of empirical salinity regressions derived from another set of reference samples (Table1).

The Benthic Quality Index (BQI) was calculated from the formula presented in Leonardsson et al. (2009), who also presents sensitivity values for a range of species estimated from a large collection of reference samples in the Kattegat and Skagerrak. The assumption behind the BQI index is that sensitive species can be characterized by occurring in samples with a high number of species, while tolerant species are found in samples with a low number of species (Rosenberg et al. 2004). After using the formula of Hurlbert (1971) to calculate the expected number of species to be found in rarefied reference samples of 50 individuals, the sensitivity of species $i$, Sens $s_{E, i}$, is estimated as the lower $5 \%$ percentile of the expected number of species found in all the reference samples in which species $i$ is present. A high sensitivity value thus signifies that a species would tend to occur in areas of high species density.

Because the sensitivity of a species in the BQI index is determined from its relative occurrence in the reference samples, sensitivity will depend on the number and mixture of reference samples available from disturbed and undisturbed environments. When Leonardsson et al. (2015) updated the sensitivities used in Leonardsson et al. (2009) they included reference samples dominated by high numbers of juveniles of one or two species. The high numbers of juveniles in these samples were found to decrease the sensitivity estimates of the other species represented in the samples. Leonardsson et al. (2015) therefore decided to abandon rarefaction in the sensitivity calculation, and changed the base for calculating the sensitivities from the rarefied number of species to the observed number of species. The new species sensitivity, $\operatorname{Sens}_{O, i}$, was defined as the $5^{\text {th }}$ percentile of the observed number of species each individual of species $i$ encountered in the reference samples where $i$ was present (Leonardsson et al. 2015). To examine the effect of this approach we also estimated the BQI indicator $B Q I_{O, j}$ for each sample based on $\operatorname{Sens}_{O, j}$, the weighted sum of the revised species sensitivities, Sens $_{O, i}$, provided by Leonardsson et al. (2015).

\subsection{Statistical modeling}


All variables were initially examined by pairwise plots and Pearson correlations to reveal the shape of potential relationships and the patterns of interaction. An analysis of covariance was then used to assess the relative importance of the variables used to calculate the DKI and BQI indicators and the Shannon index, while log linear mixed effects models were used to analyze the relationships between the indicators and environmental variables. The log linear mixed effects models used log trawling intensity, EUNIS habitat, log depth and log salinity as fixed effects while station and year were assumed to be random effects considered to reflect random differences in community attributes between stations as well as random inter-annual changes in benthic recruitment success. The analyses of the mixed models were performed in R (R Core Team 2015) using the lme4 and lmerTest packages (Bates et al. 2015). Residual plots and Q-Q plots were inspected for deviations from homoscedasticity and normality. If necessary, variables were $\log (\mathrm{x}+1)$ rather than $\log$ transformed to include zero observations. Parameter estimates were obtained using restricted maximum likelihood and significant variables were identified using backwards elimination of model terms. Alternative model versions were compared using maximum likelihood and Bonferroni adjusted likelihood ratio tests. Only natural logarithms were used.

The initial correlation analysis revealed a linear and highly significant relationship between $\log$ density and $\log$ species density $(\mathrm{r}=0.75, \mathrm{df}=144, \mathrm{P}<0.001$, Figure 3$)$ indicating that it was necessary to standardize species density to account for differences in the number of individuals recorded per sample across stations and years.

When only a small fraction of the individuals in a habitat or community is sampled, the number of species recorded provides an underestimate of total species richness which is biased against rare species. This problem was first described for marine benthos by Sanders (1968) and is often solved by individual-based rarefaction where the number of species observed is standardized to the expected number of species observed in a sample containing the same number of individuals, $n$, as the smallest sample in the group of samples being compared. Rarefying a sample from $\mathrm{N}$ to $\mathrm{n}$ individuals can mathematically be solved as a combinatorial problem providing an analytical formula for estimating the expected number of species in a random sample of $\mathrm{n}$ individuals drawn from a larger $\mathrm{N}$ individual sample (Hurlbert 1971, Heck et al. 1975). This, however, assumes that the spatial distribution of the individuals in the environment is random. If the spatial distribution is patchy, rarefaction of 
large samples tends to overestimate the number of species in small samples (Gotelli \& Colwell 2011). Previous investigations have found that the distribution of benthos in the Kattegat is patchy (Josefson 2016). Furthermore, our samples contained between 15 and 547 individuals necessitating us to rarefy all samples to 15 individuals. Instead of using rarefaction to standardize the number of species prior to our statistical analysis we therefore decided to include a species accumulation curve directly in the statistical model.

A species accumulation curve describes the curvilinear relationship between the number of individuals sampled and the number of species identified. Following the approach of Azovsky (2011) we used a power function to describe this relationship and linearized it by using log species density and log density in the analysis. This allowed us to use the linear mixed effects model to investigate whether trawling intensity significantly affected the relationship. Note that a species accumulation curve generally is used to express the relationship between the number of species identified and the cumulative number of samples or individuals examined from a particular habitat or community (see Gotelli \& Colwell 2001). Here we assume that a single species accumulation curve can be used to model samples from different locations and environmental conditions when environmental covariates and random effects of year and stations are simultaneously accounted for.

To examine how removal of species and individuals due e.g. to trawling might affect the shape of the accumulation curve, we also developed a simple stochastic benthic community model where a lognormally distributed species density distribution was randomly generated for 100 species, using the same mean and standard deviation as found in the samples (mean=1.3, stdev=1.3). We then sequentially removed the most abundant, the least abundant, or a randomly selected species from the community and fitted species accumulation curves to the results. We also investigated the effect of removing different proportions of the individuals from all of the species.

\section{Results}

The pairwise plots and Pearson correlations reveal important and significant linkages between the independent and dependent variables. The most significant interactions are 
presented in Figures 2 to 4 and the full correlation matrix is shown in the supplementary material (Figure S1). $\log N_{j}, \log S_{j}, D K I_{j}, B Q I_{E, j}$, and $S e n s_{E, j}$ were all negatively related to $\log$ trawling intensity, while $S_{e n s_{O, j}}$ was significantly positively correlated to log trawling intensity, and the Shannon ${ }_{j}, A M B I_{j}$, and $B Q I_{O, j}$ indices did not change significantly with log trawling intensity (Figure 2). Log species density, $\log S_{j}$, and $\log$ density, $\log N_{j}$, were highly significantly positively correlated (Figure 3). Furthermore, trawling intensity and $B Q I_{O}$ were positively related to salinity, while both $D K I$ and $B Q I_{E}$ declined with salinity (Figure 4).

The analysis of covariance showed that $54 \%$ of the observed across sample variation in the $D K I$ indicator was attributed to variation in the Shannon index, and $37 \%$ was attributed to salinity (Table 2). The Shannon index was dominated by changes in S which explained $69 \%$ of the variation of the index. The variation of the $B Q I_{E}$ was significantly related to changes in both $\log S_{j}$ and in the Sensitivity index, Sens $_{E}$, which explained $68 \%$ and $27 \%$ of the variation in the indicator, respectively. The same two indices affected the $B Q I_{O}$ where they explained $56 \%$ and $40 \%$ of the variation, respectively.

The linear mixed effects model confirmed that $\log N$ was highly significantly negatively related to log trawling intensity (Table 3). This effect was not just caused by a few stations. Removing the random station effect from the model and estimating a separate slope for each station revealed that $\log N$ declined with log trawling intensity on 18 of the 22 stations, and that the decline was statistically significant for 11 stations. $\log S$ was found to be linearly and highly significantly positively related to $\log N$, but not to $\log$ trawling intensity, nor to any of the other environmental variables. There was furthermore no significant interaction between the slope of this relationship and log trawling intensity. The linear mixed-effects model showed that the DKI indicator responded significantly to salinity, while the AMBI and Shannon indices neither responded significantly to log trawling intensity nor to any of the other environmental variables. The $B Q I_{E}$ and its associated sensitivity index both responded significantly to log trawling intensity, but not to log salinity or log depth (Table 3). This relationship disappeared when species sensitivities were based on the observed number of species. $B Q I_{O}$ did not respond significantly to any of the explanatory variables, while Senso was highly significantly related to salinity. Table 4 provides a full account of the model 
reduction including AIC-values (Akaikes Information Criteria; AIC) and significance of model comparisons.

Using the stochastic benthic simulation model revealed that linear relationships between log density and log species density could indeed be generated by removing either species or individuals from a simulated assemblage. The linear relationships had slopes between 0.7 and 1.5 depending on whether species were removed at random or according to ranked abundance (Figure 5). Removing a fixed proportion of the individuals from each species generated a slope in the species abundance regression of 0.50 , not significantly different from the slope of 0.53 estimated from the data (Table 3 ).

\section{Discussion}

\subsection{Indicator performance}

The DKI indicator was found to be significantly negatively related to salinity, but not to trawling. This response was puzzling, because neither the AMBI nor the Shannon index responded significantly to any of the fixed variables included in the mixed effects model. The significant salinity response of the DKI may, however, have been introduced by the salinity standardization which was done without considering the potential effects of differences in trawling intensity, eutrophication, and frequency of hypoxia events that could have influenced density and species density at each of the reference sampling stations. Using salinity as the sole explanatory variable in the standardization may produce a salinity corrected indicator where salinity unintendedly provides the best explanation for the changes observed. In the Kattegat, most of the Nephrops trawl fishery takes place below the halocline in the northern deeper parts, where salinity is higher than in the shallower southern part, and salinity and trawling intensity is therefore positively correlated $(\mathrm{r}=0.52, \mathrm{df}=146, \mathrm{P}<2.72 \mathrm{e}-11$, Figure 4). The standardization may thus inadvertently have removed the effect of bottom trawling and explained it as an effect of salinity. Adding a log trawling intensity term to the reduced DKI model where salinity was the only fixed term did not improve the goodness of fit (ANOVA, $\mathrm{P}=0.23, \mathrm{df}=1$ ) although salinity and log trawling intensity are significantly and positively related. 
The only macrobenthos indicator that responded significantly to trawling intensity in the linear mixed effects model was the $B Q I_{E}$. The response was negative and highly significant and was caused by a combination of declines in the average species sensitivity and in the number of species recorded per station (Figure 2). The closely related $B Q I_{O}$ indicator did not respond. The main difference between the two indicators is the way that species sensitivities are calculated. The $B Q I_{E}$ uses species sensitivities based on rarefied species density estimates, while the $B Q I_{O}$ uses the observed number of species without rarefaction. Whether or not to rarefy the species density estimates in the sensitivity calculation has previously been subject to some debate. Fleischer et al. (2007) found the BQI, as defined by Rosenberg et al. (2004), to be sensitive to sampling effort and therefore recommended to rarefy all species density estimates used in the formula, a practice subsequently followed e.g. by Fleischer \& Zettler(2009), Grémare et al. (2009) and Chuševè et al. (2016). Leonardsson et al. (2009), however, retained the practice of only rarefying the species density estimates in the reference samples used for estimating species sensitivities, but not the number of species recorded at each station $\left(B Q I_{E}\right)$, while Leonardsson et al. (2015) decided not to rarefy any of the species density estimates $\left(B Q I_{O}\right)$, because this led to very low sensitivity estimates for species occurring in reference samples dominated by high numbers of juveniles of one or few species. There may be reasons for using the observed number of species to calculate sensitivities during the period when larvae settle and juveniles are abundant, but our results (see Figure 2) show that this can lead to a significant positive relationship between trawling intensity and sensitivity, and therefore decrease the ability of the BQI indicator to monitor the impacts of fisheries induced mortality. Using the revised unrarefied species sensitivity values from Leonardsson et al. (2015), the abundance weighted overall sensitivity and indicator values were no longer significantly related to trawling. We cannot distinguish whether this was due to the inclusion of samples from the settling period, where the effect of local pressures at the seabed such as bottom trawling may not yet have affected species densities, or whether it was caused by using unrarefied reference samples.

The sensitivity, species diversity, and density components of the multi-metric indicators we have analyzed are contained in most of the national quality indicators of marine macrobenthos that are used to define and monitor the ecological status of coastal and marine waters throughout Europe. However, the species diversity and in some cases also the 
sensitivity indices depend on comparable estimates of species density across stations and years. Species density influenced the DKI indicator substantially through the Shannon index, and explained more than half the variation in the $B Q I_{E}$ indicator and the Shannon indices. Only the $B Q I_{O}$ indicator was more sensitive to changes in the weighted species sensitivities at each sampling station than to log species density.

We furthermore found log species density to be highly significantly related to log density. If density varies between years due to natural differences in larval recruitment, the indicators are likely to provide a variable background for estimating of how species diversity may respond to anthropogenic pressures acting on the seafloor, such as bottom trawling. Finally, the linear mixed effects model explained $78 \%$ of the variation in the density data, and $72 \%$ of the variation of the $B Q I_{E}$ (Table 4). Based on these results, we thus find the density of benthic invertebrates to be a better indicator of bottom trawling than any of the present indicators used to monitoring the ecological quality of soft-bottom macrobenthos in the Kattegat.

\subsection{Methodological implications}

It is often forgotten that quantitative sampling devices such as bottom grabs and corers only provide a count of the number of species per surface area sampled and not an un-biased estimate of the total number of species present in the habitat sampled (Gotelli \& Colwell 2001). The difficulty arises because the number of individuals caught per sample limits the number of species that can be recorded per sample, generating a causal link between species density and individual density. When small bottom corers, such as the Haps, are used a typical sample may contain between 10 and 100 individuals, while more than 1000 benthic macroinvertebrate species have been recorded in the Kattegat and western Baltic (HELCOM 2012). Clearly only a fraction of these species will be recorded in a single sample. Exactly how many depends on the size of the local species pool, the spatial distribution of the individuals and/or species, and the number of individuals caught.

By simulating the relationship between species density and individual density in bottom samples we confirmed that the exponent of the species accumulation curve was sensitive to whether species were orderly or randomly removed. The slope in double-logarithmic plots of this relationship was steepest when the least abundant species were sequentially removed and shallowest when all species abundances were gradually reduced in the same proportion. 
400

401

402

403

404

405

406

407

408

409

410

411

412

413

414

415

416

417

418

419

420

421

422

423

424

425

426

427

428

429

430

Interestingly, the slope generated by the analysis of the empirical data was not significantly different from the slope generated by simulating a proportional reduction in abundance for all species (Figure $5 d$ ).

Log species density and log density were both highly significantly correlated to each other and to trawling intensity, but trawling did not seem to affect log species density above the effect generated by its reduction of log density. When log density was included in the model of log species density, the impact of trawling intensity on log species density was no longer significant. There was also no significant effect of trawling intensity on the slope of the relationship between log density and log species density. This suggests that log species density is negatively affected by trawling simply because trawling reduces the density of individuals. Had trawling affected the most abundant species more than the less abundant the slope of the relationship between log density and log species density would probably have steepened in response to trawling as shown by the simulations. The slope at the base of the rarefaction curve has been shown to be equivalent to Hurlbert's probability of interspecific encounter, which is a common sample size independent measure of evenness (Olszewski 2004, Chase \& Knight 2013). Hence, because a rarefaction curve would correspond to the lower part of the species accumulation curve a constant logged species accumulation slope suggests that evenness is unaffected by fishing.

Although the slope of the log species accumulation curve thus appears to be resilient to trawling, several decades of trawling could nevertheless have led to a gradual change in species composition that would be important to monitor, but difficult to identify with the present indicators. For instance, if changes in trophic interaction and interspecific competition resulted in species replacements, but the overall relationship between density and species density remained the same, indicators neglecting species identity might not respond. However, previous investigations in the Kattegat have not suggested that species replacements are likely to have happened. These investigations found inter-annual changes in benthos abundance and recruitment to affect all species and all investigated locations similarly, and suggested that a common factor could be operating, perhaps linked to the deposition of organic material on the seabed (Josefson 1987, Josefson et al. 1993) or to general climatic oscillations (Tunberg \& Nelson 1998). Furthermore, Pommer et al. (2016) found no relationship between bottom trawling intensity and changes in macrobenthos 
community composition in the Kattegat. Zettler et al. (2017) investigated a 30 year timeseries of benthos data from the western Baltic and concluded that benthic communities were influenced by a multitude of environmental variables and did not appear to be tightly controlled by any single environmental driver even within a restricted spatial area. We conclude that this calls for including environmental drivers as well as random year and station effects in the analyses in order to make anthropogenic impacts identifiable on a background of substantial natural variation.

\subsection{Perspectives}

A new generation of indicators is now being developed for monitoring macrobenthos status in relation to bottom trawling and MSFD requirements. Some of these indicators are based on changes in species or trait compositions (e.g. longevity) (Hiddink et al. 2006, Eigaard et al. 2017), and may suffer from the same sampling problems as the classical species density and diversity based indicators used to assess Good Ecological Status in relation to the WFD. We hope to have demonstrated that mixed effects models provide a possibility for dealing with some of these problems and allow a more precise translation of the qualitative descriptors of the directives into quantitative measurable goals. Using linear mixed-effects models of density solves the problem of standardization across different sources of variation by allowing incorporation of random effects of e.g. space (station) and time (month, year), generated by station specific differences in environmental conditions and by inter-annual differences in recruitment success, as well as fixed effects generated by quantified variables such as salinity, depth, bottom habitat and trawling intensity. Incorporation of environmental covariates and random effects allows changes in density to be mechanistically linked to differences in anthropogenic and natural pressures. Direct effects of fisheries generated mortality on macrobenthos communities can potentially be separated from indirect effects by examining how e.g. growth or reproduction is affected by trawling intensity, providing a possibility for defining limit reference points of relative densities below which offspring production can no longer secure replacement.

Finally, relative density could prove useful as an indicator of bottom trawling in parallel with other indicators. The AMBI has been shown to respond consistently to organic enrichment and pollution (Borja et al. 2015), but has been found to be less responsive to physical 
462 disturbance (Muxika et al. 2005). We found no significant correlation between AMBI and 463 either density $(r=0.062, p=0.46, d f=144)$, log density $(r=0.10, p=0.22, d f=144)$ or $\log$ trawling 464 intensity ( $\mathrm{r}=-0.002, \mathrm{p}=0.98, \mathrm{df}=144)$ in the Kattegat data showing that although AMBI might 465 be used as an indicator of chemical pollution, eutrophication and organic enrichment it is 466 unaffected by trawling intensity. Using several uncorrelated indicators, each responding to a 467 specific pressure, might provide the most unequivocal translation of the impacts of 468 anthropogenic pressures to ecosystem status and could help managers prioritize the 469 measures needed to achieve Good Ecological and Environmental Status in relation to the WFD 470 and MSFD targets for soft-bottom macrobenthos communities.

472 Acknowledgements

473 Thanks to Jens Deding, Danish Environmental Agency, for providing the benthos data, to 474 Jørgen L.S. Hansen, Danish Centre For Environment and Energy, for initial discussions and 475 cooperation, and to Kasper Kristensen and Ciaran McLaverty, both DTU Aqua, for help with 476 the statistics and for suggesting corrections and improvements to an earlier version of the 477 manuscript. Thanks also to one of the reviewers whose thorough comments provided much 478 valuable input to the final version. The work was funded by the EU-FP7 project "BENTHIS" 479 (grant agreement number 312088) and DTU Aqua. 
References

Al-Hamdani, Z. K., Reker, J., Leth, J. O., Reijonen, A., Kotilainen, A. T., \& Dinesen, G. E. (2007). Development of marine landscape maps for the Baltic Sea and the Kattegat using geophysical and hydrographical parameters. Geological Survey of Denmark and Greenland Bulletin, 13, 61-64.

Azovsky, A. I. (2011). Species-area and species-sampling effort relationships: disentangling the effects. Ecography, 34(1), 18-30.

Bates D., Maechler M., Bolker B. \& Walker S. (2015). Fitting Linear Mixed-Effects Models Using Ime4. Journal of Statistical Software, 67(1), 1-48. doi:10.18637/jss.v067.i01.

Birk, S., Bonne, W., Borja, A., Brucet, S., Courrat, A., Poikane, S., Solimini, A., van de Bund, W. Zampoukas, N., \& Hering, D. (2012). Three hundred ways to assess Europe's surface waters: an almost complete overview of biological methods to implement the Water Framework Directive. Ecological Indicators, 18, 31-41.

Borja, A., Franco, J., \& Pérez, V. (2000). A marine biotic index to establish the ecological quality of soft-bottom benthos within European estuarine and coastal environments. Marine Pollution Bulletin, 40(12), 1100-1114.

Borja Á., Franco F., Valencia V., Bald J., Muxika I., Belzunce M.J., Solaun O. (2004). Implementation of the European Water Framework Directive from the Basque country (northern Spain): a methodological approach. Marine Pollution Bulletin, 48 (3-4), 209218.

Borja, A., Josefson, A. B., Miles, A., Muxika, I., Olsgard, F., Phillips, G., Rodríguez,G. \& Rygg, B. (2007). An approach to the intercalibration of benthic ecological status assessment in the North Atlantic ecoregion, according to the European Water Framework Directive. Marine Pollution Bulletin 55(1), 42-52.

Borja, A., \& Dauer, D. M. (2008). Assessing the environmental quality status in estuarine and coastal systems: comparing methodologies and indices. Ecological indicators, 8(4), 331337.

Borja, A., Miles, A., Occhipinti-Ambrogi, A., \& Berg, T. (2009). Current status of macroinvertebrate methods used for assessing the quality of European marine waters: implementing the Water Framework Directive. Hydrobiologia, 633(1), 181-196. 
Borja, A., Elliott, M., Andersen, J. H., Cardoso, A. C., Carstensen, J., Ferreira, J. G., ... \& Uusitalo, L. (2013). Good Environmental Status of marine ecosystems: What is it and how do we know when we have attained it?. Marine Pollution Bulletin, 76(1), 16-27.

Borja, Á., Marín, S. L., Muxika, I., Pino, L., \& Rodríguez, J. G. (2015). Is there a possibility of ranking benthic quality assessment indices to select the most responsive to different human pressures?. Marine pollution bulletin, 97(1), 85-94.

Cardinale, M., Hagberg, J., Svedäng, H., Bartolino, V., Gedamke, T., Hjelm, J., ... \& Norén, F. (2010). Fishing through time: population dynamics of plaice (Pleuronectes platessa) in the Kattegat-Skagerrak over a century. Population ecology, 52(2), 251-262.

Chase, J. M., \& Knight, T. M. (2013). Scale-dependent effect sizes of ecological drivers on biodiversity: why standardised sampling is not enough. Ecology letters, 16(s1), 17-26.

Chuševė, R., Nygård, H., Vaičiūtė, D., Daunys, D., \& Zaiko, A. (2016). Application of signal detection theory approach for setting thresholds in benthic quality assessments. Ecological Indicators, 60, 420-427.

Clark, M. R., Althaus, F., Schlacher, T. A., Williams, A., Bowden, D. A., \& Rowden, A. A. (2016). The impacts of deep-sea fisheries on benthic communities: a review. ICES Journal of Marine Science: Journal du Conseil, 73(suppl 1), i51-i69.

Collie, J., Hiddink, J. G., Kooten, T., Rijnsdorp, A. D., Kaiser, M. J., Jennings, S., \& Hilborn, R. (2016). Indirect effects of bottom fishing on the productivity of marine fish. Fish and Fisheries. DOI: 10.1111/faf.12193

Danish AgriFish Agency (2016). Yearbook of Fishery Statistics 2015. Danish AgriFish Agency. Ministry of Environment and Food. December 2016. 278 pp.

van Denderen, P. D., Hintzen, N. T., Rijnsdorp, A. D., Ruardij, P., \& van Kooten, T. (2014). Habitat-specific effects of fishing disturbance on benthic species richness in marine soft sediments. Ecosystems, 17(7), 1216-1226.

van Denderen, P. D., Bolam, S. G., Hiddink, J. G., Jennings, S., Kenny, A., Rijnsdorp, A. D., \& van Kooten, T. (2015). Similar effects of bottom trawling and natural disturbance on composition and function of benthic communities across habitats. Marine Ecology Progress Series, 541, 31-43.

Eigaard, O. R., Bastardie, F., Hintzen, N. T., Buhl-Mortensen, L., Buhl-Mortensen, P., Catarino, R., Dinesen, G. E., ... \& Rijnsdorp, A.D. (2017). The footprint of bottom trawling in European 
waters: distribution, intensity, and seabed integrity. ICES Journal of Marine Science: Journal du Conseil, 74(3), 847-865

Eigaard, O. R., Bastardie, F., Breen, M., Dinesen, G. E., Hintzen, N. T., Laffargue, P., ... \& Polet, H. (2016). Estimating seabed pressure from demersal trawls, seines, and dredges based on gear design and dimensions. ICES Journal of Marine Science: Journal du Conseil, 73(suppl 1), i27-i43.

Fleischer, D., Grémare, A., Labrune, C., Rumohr, H., Berghe, E. V., \& Zettler, M. L. (2007). Performance comparison of two biotic indices measuring the ecological status of water bodies in the Southern Baltic and Gulf of Lions. Marine Pollution Bulletin, 54(10), 15981606.

Fleischer, D., \& Zettler, M. L. (2009). An adjustment of benthic ecological quality assessment to effects of salinity. Marine Pollution Bulletin, 58(3), 351-357.

Gotelli, N.J. \& Colwell R.K. (2001). Quantifying biodiversity: procedures and pitfalls in the measurement and comparison of species richness. Ecology letters, 4(4), 379-391.

Gotelli, N. J., \& Colwell, R. K. (2011). Estimating species richness. In Magurran A. E., McGill B. J.(eds.): Biological diversity: frontiers in measurement and assessment, 39-54. Oxford, UK: Oxford University Press.

Gray, J. S., Wu, R. S. S., \& Or, Y. Y. (2002). Effects of hypoxia and organic enrichment on the coastal marine environment. Marine Ecology Progress Series, 238, 249-279.

Grémare, A., Labrune, C., Vanden Berghe, E., Amouroux, J. M., Bachelet, G., Zettler, M. L., ... \& Deflandre, B. (2009). Comparison of the performances of two biotic indices based on the MacroBen database. Marine Ecology-Progress Series, 382, 297-311.

Heck, K. L., van Belle, G., \& Simberloff, D. (1975). Explicit calculation of the rarefaction diversity measurement and the determination of sufficient sample size. Ecology, 56(6), 1459-1461.

HELCOM (2012). Checklist of Baltic Sea Macro-species. Baltic Sea Environment Proceedings No. 13.

Henriksen, P., Josefson, A., Hansen, J.W., Krause-Jensen, D., Dahl, K. \& Dromph, K. (2014). Danish contribution to the EU Water Framework Directive intercalibration phase 2. Aarhus University, DCE - Danish Centre for Environment and Energy, 36 pp. Technical Report from DCE - Danish Centre for Environment and Energy No.

37. http://dce2.au.dk/pub/TR37.pdf 
Hiddink, J. G., Jennings, S., \& Kaiser, M. J. (2006). Indicators of the ecological impact of bottomtrawl disturbance on seabed communities. Ecosystems, 9(7), 1190-1199.

Hinz, H., Prieto, V., \& Kaiser, M. J. (2009). Trawl disturbance on benthic communities: chronic effects and experimental predictions. Ecological Applications, 19(3), 761-773.

Hintzen, N. T., Piet, G. J., \& Brunel, T. (2010). Improved estimation of trawling tracks using cubic Hermite spline interpolation of position registration data. Fisheries Research, 101(1), 108-115.

Hurlbert, S.H. (1971). The non-concept of species diversity: a critique and alternative parameters. Ecology, 52, 577-586.

Josefson, A. B. (1987). Large-scale patterns of dynamics in subtidal macrozoobenthic assemblages in the Skagerrak: effects of a production-related factor. Mar. Ecol. Prog. Ser, 38, 13-23.

Josefson, A. B., Jensen, J. N., \& Ærtebjerg, G. (1993). The benthos community structure anomaly in the late 1970s and early 1980s-a result of a major food pulse?. Journal of Experimental Marine Biology and Ecology, 172(1), 31-45.

Josefson, A. B., Blomqvist, M., Hansen, J. L., Rosenberg, R., \& Rygg, B. (2009). Assessment of marine benthic quality change in gradients of disturbance: comparison of different Scandinavian multi-metric indices. Marine Pollution Bulletin, 58(9), 1263-1277.

Josefson, A.B. and Hansen J.L.S. (2014) Blødbundsfauna. Teknisk anvisning M19. DCE. Aarhus Universitet. $15 \mathrm{pp}$.

Josefson, A. B. (2016). Species Sorting of Benthic Invertebrates in a Salinity GradientImportance of Dispersal Limitation. PloS one, 11(12), e0168908.

Kaiser, M. J., Clarke, K. R., Hinz, H., Austen, M. C. V., Somerfield, P. J., \& Karakassis, I. (2006). Global analysis of response and recovery of benthic biota to fishing. Marine Ecology Progress Series, 311, 1-14.

Kanneworff, E. \& Nicolaisen, W. (1973). The 'haps' a frame-supported corer. Ophelia, 10, 119129.

Leonardsson, K., Blomqvist, M., \& Rosenberg, R. (2009). Theoretical and practical aspects on benthic quality assessment according to the EU-Water Framework Directive-examples from Swedish waters. Marine Pollution Bulletin, 58(9), 1286-1296. 
603

604

605

606

607

608

609

610

611

612

613

614

615

616

617

618

619

620

621

622

623

624

625

626

627

628

629

630

631

632

633

634

Leonardsson, K., Blomqvist, M., Magnusson, M., Wikström, A., \& Rosenberg, R. (2015). Calculation of species sensitivity values and their precision in marine benthic faunal quality indices. Marine Pollution Bulletin, 93(1), 94-102.

Muntadas, A., de Juan, S., \& Demestre, M. (2016). Assessing functional redundancy in chronically trawled benthic communities. Ecological Indicators, 61, 882-892.

Muxika, I., Borja, A., \& Bonne, W. (2005). The suitability of the marine biotic index (AMBI) to new impact sources along European coasts. Ecological indicators, 5(1), 19-31.

Neumann H, Diekmann R, Kröncke I (2016).The influence of habitat characteristics and fishing effort on functional composition of epifauna in the south-eastern North Sea. Estuarine, Coastal and Shelf Sciences 169: 182-194.

Olszewski, T. D. (2004). A unified mathematical framework for the measurement of richness and evenness within and among multiple communities. Oikos, 104(2), 377-387.

Pearson, T. H., and Rosenberg, R. (1978). Macrobenthic succession in relation to organic enrichment and pollution of the marine environment. Oceanogr. Mar. Biol. Ann. Rev, 16, 229-311.

Pinto, R., Patricio, J., Baeta, A., Fath, B.D., Neto, J.M., Marques, J.C., (2009). Review and evaluation of estuarine biotic indices to assess benthic condition. Ecological Indicators 9 , $1-25$.

Pommer, C. D., Olesen, M., \& Hansen, J. L. (2016). Impact and distribution of bottom trawl fishing on mud-bottom communities in the Kattegat. Marine Ecology Progress Series, 548, 47-60.

Queirós, A. M., Hiddink, J. G., Kaiser, M. J., \& Hinz, H. (2006). Effects of chronic bottom trawling disturbance on benthic biomass, production and size spectra in different habitats. Journal of Experimental Marine Biology and Ecology, 335(1), 91-103.

Quintino, V., Elliott, M., \& Rodrigues, A. M. (2006). The derivation, performance and role of univariate and multivariate indicators of benthic change: case studies at differing spatial scales. Journal of Experimental Marine Biology and Ecology, 330(1), 368-382.

R Core Team (2015). R: A language and environment for statistical computing. R Foundation for Statistical Computing, Vienna, Austria. URL https://www.R-project.org/

Rice, J., Arvanitidis, C., Borja, A., Frid, C., Hiddink, J. G., Krause, J., Lorance, P., Ragnarsson, S.A., Sköld, M., Trabucco, B. \& Enserink, L. (2012). Indicators for sea-floor integrity under the European Marine Strategy Framework Directive. Ecological indicators, 12(1), 174-184. 
635 636 637 638 639 640 641 642 643 644 645 646 647 648 649 650 651 652 653 654 655 656 657 658 659 660 661 662 663 664 665 666

Riemann, B., Carstensen, J., Dahl, K., Fossing, H., Hansen, J. W., Jakobsen, H. H., ... \& Timmermann, K. (2016). Recovery of Danish coastal ecosystems after reductions in nutrient loading: a holistic ecosystem approach. Estuaries and Coasts, 39(1), 82-97.

Rijnsdorp, A. D., Bastardie, F., Bolam, S. G., Buhl-Mortensen, L., Eigaard, O. R., Hamon, K. G., ... \& Laffargue, P. (2016). Towards a framework for the quantitative assessment of trawling impact on the seabed and benthic ecosystem. ICES Journal of Marine Science: Journal du Conseil, 73(suppl 1), i127-i138.

Rosenberg, R., Blomquist, M., Nilsson, H.C., Cederwall, H., Dimming, A. (2004). Marine quality assessment by use of benthic species abundance distributions: a proposed new protocol within the European Union Water Framework Directive. Marine Pollution Bulletin. 49, 728-739.

Sanders, H. L. (1968). Marine benthic diversity: a comparative study. The American Naturalist, 102(925), 243-282.

Tipper, J. (1979). Rarefaction and Rarefiction -The Use and Abuse of a Method in Paleoecology. Paleobiology, 5(4), 423-434.

Shannon, C.E., Weaver, W. (1963). The Mathematical Theory of Communication. University of Illinois Press, Urbana, 117 pp.

Svedäng, H., Stål, J., Sterner, T., \& Cardinale, M. (2010). Consequences of subpopulation structure on fisheries management: cod (Gadus morhua) in the Kattegat and Öresund (North Sea). Reviews in Fisheries Science, 18(2), 139-150.

Tillin, H. M., Hiddink, J. G., Jennings, S., \& Kaiser, M. J. (2006). Chronic bottom trawling alters the functional composition of benthic invertebrate communities on a sea-basin scale. Marine Ecology Progress Series, 318, 31-45.

Tunberg, B. G., \& Nelson, W. G. (1998). Do climatic oscillations influence cyclical patterns of soft bottom macrobenthic communities on the Swedish west coast?. Marine Ecology Progress Series, 170, 85-94.

Van Hoey, G., Borja, A., Birchenough, S., Buhl-Mortensen, L., Degraer, S., Fleischer, D., \& Schröder, A. (2010). The use of benthic indicators in Europe: from the Water Framework Directive to the Marine Strategy Framework Directive. Marine Pollution Bulletin, 60(12), 2187-2196

Vincent, C., Heinrich, H., Edwards, A., Nygaard, K., Haythornthwaite, J. (2002). Guidance on typology, reference conditions and classification systems for transitional and coastal 
waters. Produced by: CIS Working Group 2.4 (COAST), Common Implementation Strategy of the Water Framework Directive, European Commission, 119 pp.

669 Zettler, M. L., Friedland, R., Gogina, M., \& Darr, A. (2017). Variation in benthic long-term data 670 of transitional waters: Is interpretation more than speculation?. PloS one, 12(4), e0175746. 


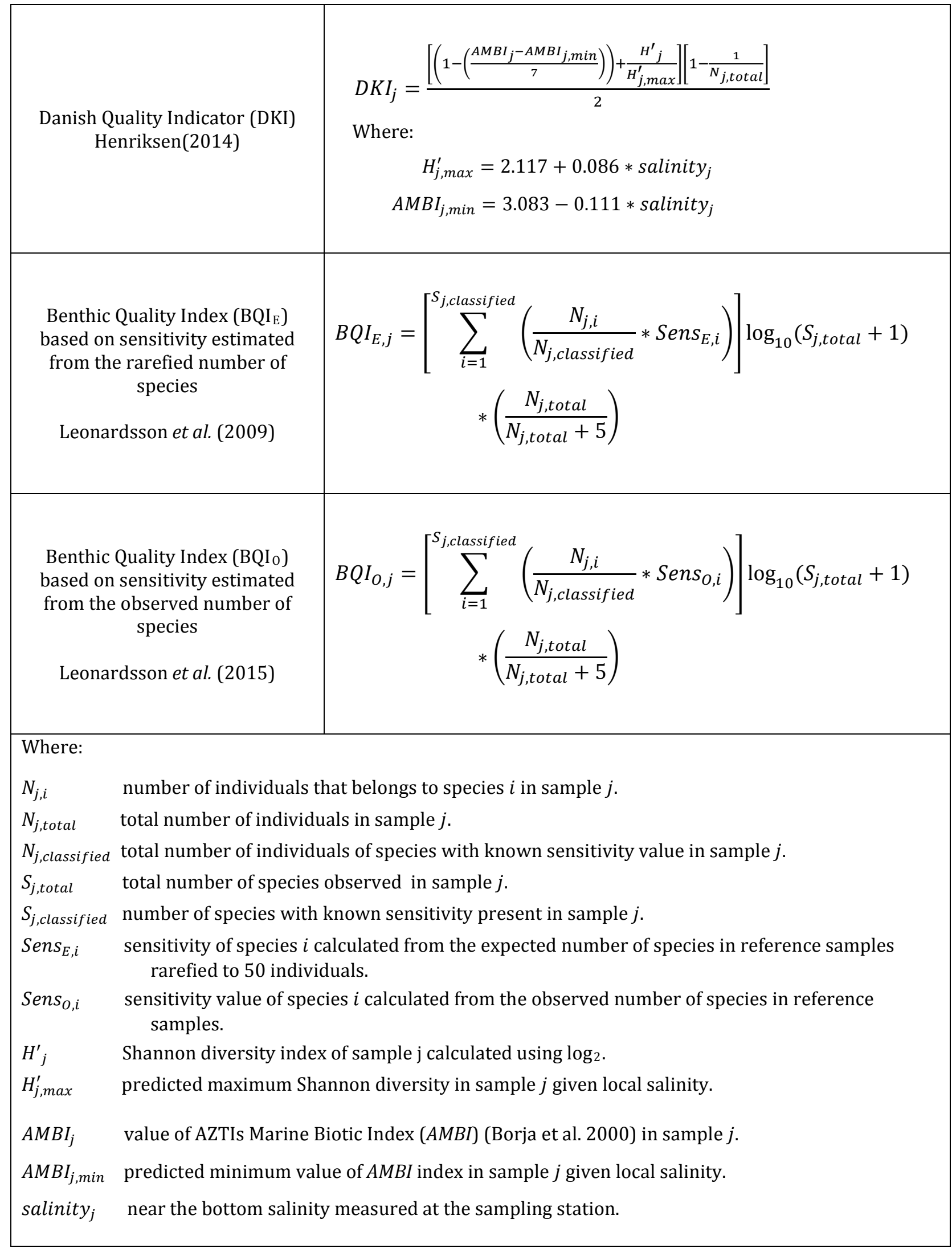


674 Table 2. Analysis of covariance of the DKI, BQI and Shannon indicators.

\begin{tabular}{|c|c|c|c|c|c|c|}
\hline Indicator & Variable & $\begin{array}{l}\text { Degrees } \\
\text { of } \\
\text { freedom }\end{array}$ & $\begin{array}{l}\text { Sum of } \\
\text { Squares }\end{array}$ & F-value & $P(>F)$ & $\begin{array}{c}\text { \% of } \\
\text { Total } \\
\text { Sum of } \\
\text { Squares }\end{array}$ \\
\hline \multirow{5}{*}{$D K I$} & $A M B I$ & 1 & 0.111 & 2584.0 & $<2 \mathrm{e}-16$ & 8 \\
\hline & $H^{\prime}$ & 1 & 0.728 & 16903.5 & $<2 \mathrm{e}-16$ & 54 \\
\hline & $1 / N$ & 1 & 0.006 & 134.9 & $<2 \mathrm{e}-16$ & 0 \\
\hline & salinity & 1 & 0.493 & 11474.9 & $<2 \mathrm{e}-16$ & 37 \\
\hline & Residuals & 141 & 0.006 & & & 0 \\
\hline \multirow{4}{*}{$B Q I_{E}$} & Sens $_{E}$ & 1 & 112.3 & 966.289 & $<2 \mathrm{e}-16$ & 27 \\
\hline & $\log S$ & 1 & 287.2 & 2470.158 & $<2 \mathrm{e}-16$ & 68 \\
\hline & $N$ & 1 & 6.3 & 54.304 & $1.29 \mathrm{E}-11$ & 1 \\
\hline & Residuals & 142 & 16.5 & & & 4 \\
\hline \multirow{4}{*}{$B Q I_{O}$} & $\operatorname{Sens}_{O}$ & 1 & 1045.9 & 2185.715 & $<2 \mathrm{e}-16$ & 56 \\
\hline & $\log S$ & 1 & 726.2 & 1592.767 & $<2 \mathrm{e}-16$ & 40 \\
\hline & $N$ & 1 & 6.9 & 14.454 & 2.13E-04 & 0 \\
\hline & Residuals & 142 & 68.0 & & & 4 \\
\hline \multirow{3}{*}{$H^{\prime}$} & $N$ & 1 & 13.3 & 116.31 & $<2 \mathrm{e}-16$ & 14 \\
\hline & $S$ & 1 & 64.5 & 565.93 & $<2 \mathrm{e}-16$ & 69 \\
\hline & Residuals & 143 & 16.3 & & & 17 \\
\hline
\end{tabular}

675

676

677 
Table 3. Result from fitting a linear mixed effects model with Year and Station as random variables and habitat, $\log ($ depth), $\log$ (salinity) and $\log$ (trawling intensity+1) as fixed independent variables to various response variables. Only the significant parameter estimates are included in the final models and table. Log stands for natural logarithm, standard error is shown in brackets, grey area signifies not investigated. Significance: ${ }^{*}: \mathrm{P}<0.05$; ${ }^{* *}: \mathrm{P}<0.01$; $* * * \mathrm{P}<0.001$

\begin{tabular}{|c|r|c|c|c|}
\hline $\begin{array}{c}\text { Response } \\
\text { variable }\end{array}$ & \multicolumn{1}{|c|}{ Intercept } & $\log N$ & $\log ($ salinity $)$ & $\log ($ trawling +1$)$ \\
\hline$D K I$ & $2.36(0.37)^{* * *}$ & & $-0.48(0.11)^{* *}$ & \\
\hline$A M B I$ & $1.71(0.06)^{* * *}$ & & & \\
\hline$H^{\prime}$ & $3.44(0.15)^{* * *}$ & & & \\
\hline$B Q I_{E}$ & $11.81(0.59)^{* * *}$ & & & $-1.14(0.32)^{* * *}$ \\
\hline$S e n s_{E}$ & $8.71(0.15)^{* * *}$ & & & $-0.35(0.11)^{* *}$ \\
\hline$B Q I_{O}$ & $16.81(0.98)^{* * *}$ & & & \\
\hline$S e n S_{O}$ & $-17.61(6.77)^{*}$ & & $9.03(1.98)^{* * *}$ & \\
\hline $\log S$ & $0.67(0.21)^{* *}$ & $0.53(0.04)^{* * *}$ & & $-0.29(0.09)^{* *}$ \\
\hline $\log N$ & $4.86(0.17)^{* * *}$ & & & \\
\hline
\end{tabular}



values. AIC is Akaike's Information Criteria and P is the probability from a likelihood ratio test that the model explains the data significantly better than the previous model with the additional term. Significance is Bonferroni corrected to account for the number of model comparisons. ${ }^{*} \mathrm{P}<0.05 ;{ }^{* *}: \mathrm{P}<0.01 ;{ }^{* * *} \mathrm{P}<0.001$. Log stands for natural logarithm.

\begin{tabular}{|c|c|c|c|}
\hline Model & $\mathrm{R}^{2}$ & AIC & $\mathrm{P}$ \\
\hline $\log N=\log$ trawl + habitat + logsalinity $+\log$ depth $+\varepsilon_{\text {station }}+\varepsilon_{\text {year }}+\varepsilon_{0}$ & 0.78 & 214.8 & \\
\hline $\log N=\log$ trawl + logsalinity $+\log$ depth $+\varepsilon_{\text {station }}+\varepsilon_{\text {year }}+\varepsilon_{0}$ & 0.78 & 211.8 & 0.383 \\
\hline $\log N=\log$ trawl + logdepth $+\varepsilon_{\text {station }}+\varepsilon_{\text {year }}+\varepsilon_{0}$ & 0.78 & 210.3 & 0.469 \\
\hline $\log N=\log$ trawl $+\varepsilon_{\text {station }}+\varepsilon_{\text {year }}+\varepsilon_{0}$ & 0.78 & 209.8 & 0.230 \\
\hline $\log N=\varepsilon_{\text {station }}+\varepsilon_{\text {year }}+\varepsilon_{0}$ & 0.77 & 217.5 & $1.8 \mathrm{e}-3^{* *}$ \\
\hline $\log S=\log N+\log$ trawl + habitat $+\log$ salinity $+\log$ depth $+\varepsilon_{\text {station }}+\varepsilon_{\text {year }}+\varepsilon_{0}$ & 0.84 & 32.4 & \\
\hline $\log S=\log N+$ habitat $+\log$ salinity $+\log$ depth $+\varepsilon_{\text {station }}+\varepsilon_{\text {year }}+\varepsilon_{0}$ & 0.84 & 30.6 & 0.652 \\
\hline $\log S=\log N+$ habitat $+\log$ depth $+\varepsilon_{\text {station }}+\varepsilon_{\text {year }}+\varepsilon_{0}$ & 0.84 & 31.6 & 0.086 \\
\hline $\log S=\log N+$ habitat $+\varepsilon_{\text {station }}+\varepsilon_{\text {year }}+\varepsilon_{0}$ & 0.84 & 34.9 & 0.022 \\
\hline $\log S=\log N+\varepsilon_{\text {station }}+\varepsilon_{\text {year }}+\varepsilon_{0}$ & 0.84 & 32.9 & 0.258 \\
\hline $\log S=\varepsilon_{\text {station }}+\varepsilon_{\text {year }}+\varepsilon_{0}$ & 0.73 & 132.7 & $2.2 \mathrm{e}-16^{* * *}$ \\
\hline$D K I=$ logtrawl + habitat + logsalinity + logdepth $+\varepsilon_{\text {station }}+\varepsilon_{\text {year }}+\varepsilon_{0}$ & 0.83 & -386.6 & \\
\hline$D K I=$ habitat + logsalinity + logdepth $+\varepsilon_{\text {station }}+\varepsilon_{\text {year }}+\varepsilon_{0}$ & 0.83 & -388.6 & 0.894 \\
\hline$D K I=$ habitat + logsalinity $+\varepsilon_{\text {station }}+\varepsilon_{\text {year }}+\varepsilon_{0}$ & 0.83 & -387.0 & 0.058 \\
\hline$D K I=$ logsalinity $+\varepsilon_{\text {station }}+\varepsilon_{\text {year }}+\varepsilon_{0}$ & 0.83 & -385.3 & 0.053 \\
\hline$D K I=\varepsilon_{\text {station }}+\varepsilon_{\text {year }}+\varepsilon_{0}$ & 0.83 & -372.5 & $1.2 \mathrm{e}-4^{* * *}$ \\
\hline$A M B I=$ logtrawl + habitat + logsalinity + logdepth $+\varepsilon_{\text {station }}+\varepsilon_{\text {year }}+\varepsilon_{0}$ & 0.33 & 166.3 & \\
\hline$A M B I=$ logtrawl + logsalinity + depth $+\varepsilon_{\text {station }}+\varepsilon_{\text {year }}+\varepsilon_{0}$ & 0.31 & 165.9 & 0.203 \\
\hline$A M B I=$ logtrawl + logdepth $+\varepsilon_{\text {station }}+\varepsilon_{\text {year }}+\varepsilon_{0}$ & 0.30 & 165.8 & 0.114 \\
\hline$A M B I=$ logdepth $+\varepsilon_{\text {station }}+\varepsilon_{\text {year }}+\varepsilon_{0}$ & 0.31 & 164.5 & 0.395 \\
\hline$A M B I=\varepsilon_{\text {station }}+\varepsilon_{\text {year }}+\varepsilon_{0}$ & 0.31 & 164.8 & 0.130 \\
\hline Shannon $=$ logtrawl + habitat + logsalinity + logdepth $+\varepsilon_{\text {station }}+\varepsilon_{\text {year }}+\varepsilon_{0}$ & 0.66 & 268.8 & \\
\hline Shannon $=$ logtrawl + habitat + logdepth $+\varepsilon_{\text {station }}+\varepsilon_{\text {year }}+\varepsilon_{0}$ & 0.66 & 266.8 & 0.834 \\
\hline Shannon $=$ logtrawl + habitat $+\varepsilon_{\text {station }}+\varepsilon_{\text {year }}+\varepsilon_{0}$ & 0.66 & 267.5 & 0.104 \\
\hline Shannon $=$ habitat $+\varepsilon_{\text {station }}+\varepsilon_{\text {year }}+\varepsilon_{0}$ & 0.66 & 267.1 & 0.207 \\
\hline Shannon $=\varepsilon_{\text {station }}+\varepsilon_{\text {year }}+\varepsilon_{0}$ & 0.66 & 269.3 & 0.042 \\
\hline$B Q I_{E}=$ logtrawl + habitat + logsalinity + logdepth $+\varepsilon_{\text {station }}+\varepsilon_{\text {year }}+\varepsilon_{0}$ & 0.73 & 580.7 & \\
\hline$B Q I_{E}=$ logtrawl + habitat + logdepth $+\varepsilon_{\text {station }}+\varepsilon_{\text {year }}+\varepsilon_{0}$ & 0.73 & 578.9 & 0.648 \\
\hline$B Q I_{E}=$ logtrawl + habitat $+\varepsilon_{\text {station }}+\varepsilon_{\text {year }}+\varepsilon_{0}$ & 0.73 & 579.2 & 0.127 \\
\hline$B Q I_{E}=$ logtrawl $+\varepsilon_{\text {station }}+\varepsilon_{\text {year }}+\varepsilon_{0}$ & 0.72 & 580.0 & 0.082 \\
\hline$B Q I_{E}=\varepsilon_{\text {station }}+\varepsilon_{\text {year }}+\varepsilon_{0}$ & 0.72 & 590.0 & $5.2 \mathrm{e}-4^{* *}$ \\
\hline Sens $_{E}=$ logtrawl + habitat + logsalinity + logdepth $+\varepsilon_{\text {station }}+\varepsilon_{\text {year }}+\varepsilon_{0}$ & 0.52 & 282.9 & \\
\hline $\operatorname{Sens}_{E}=$ logtrawl + habitat + logdepth $+\varepsilon_{\text {station }}+\varepsilon_{\text {year }}+\varepsilon_{0}$ & 0.52 & 284.0 & 0.078 \\
\hline Sens $_{E}=$ logtrawl + habitat $+\varepsilon_{\text {station }}+\varepsilon_{\text {year }}+\varepsilon_{0}$ & 0.52 & 286.1 & 0.043 \\
\hline Sens $_{E}=\log$ trawl $+\varepsilon_{\text {station }}+\varepsilon_{\text {year }}+\varepsilon_{0}$ & 0.52 & 284.8 & 0.194 \\
\hline Sens $_{E}=\varepsilon_{\text {station }}+\varepsilon_{\text {year }}+\varepsilon_{0}$ & 0.50 & 293.3 & $0.001 * *$ \\
\hline$B Q I_{O}=$ logtrawl + habitat + logsalinity + logdepth $+\varepsilon_{\text {station }}+\varepsilon_{\text {year }}+\varepsilon_{0}$ & 0.71 & 774.4 & \\
\hline$B Q I_{O}=$ logtrawl + habitat + logdepth $+\varepsilon_{\text {station }}+\varepsilon_{\text {year }}+\varepsilon_{0}$ & 0.71 & 772.1 & 0.107 \\
\hline$B Q I_{O}=$ logdepth + habitat $+\varepsilon_{\text {station }}+\varepsilon_{\text {year }}+\varepsilon_{0}$ & 0.71 & 769.9 & 0.096 \\
\hline$B Q I_{O}=$ logdepth $+\varepsilon_{\text {station }}+\varepsilon_{\text {year }}+\varepsilon_{0}$ & 0.71 & 763.5 & 0.035 \\
\hline$B Q I_{O}=\varepsilon_{\text {station }}+\varepsilon_{\text {year }}+\varepsilon_{0}$ & 0.71 & 760.1 & 0.219 \\
\hline Sens $_{O}=$ logtrawl + habitat + logsalinity + logdepth $+\varepsilon_{\text {station }}+\varepsilon_{\text {year }}+\varepsilon_{0}$ & 0.76 & 529.4 & \\
\hline Sens $_{O}=$ logtrawl + logsalinity + logdepth $+\varepsilon_{\text {station }}+\varepsilon_{\text {year }}+\varepsilon_{0}$ & 0.76 & 524.3 & 0.830 \\
\hline Sens $_{O}=$ logsalinity + logdepth $+\varepsilon_{\text {station }}+\varepsilon_{\text {year }}+\varepsilon_{0}$ & 0.76 & 523.0 & 0.405 \\
\hline Sens $_{o}=$ logsalinity $+\varepsilon_{\text {station }}+\varepsilon_{\text {year }}+\varepsilon_{0}$ & 0.76 & 527.0 & 0.014 \\
\hline Sens $_{O}=\varepsilon_{\text {station }}+\varepsilon_{\text {year }}+\varepsilon_{0}$ & 0.76 & 540.4 & $8.6 \mathrm{E}-5^{* * *}$ \\
\hline
\end{tabular}




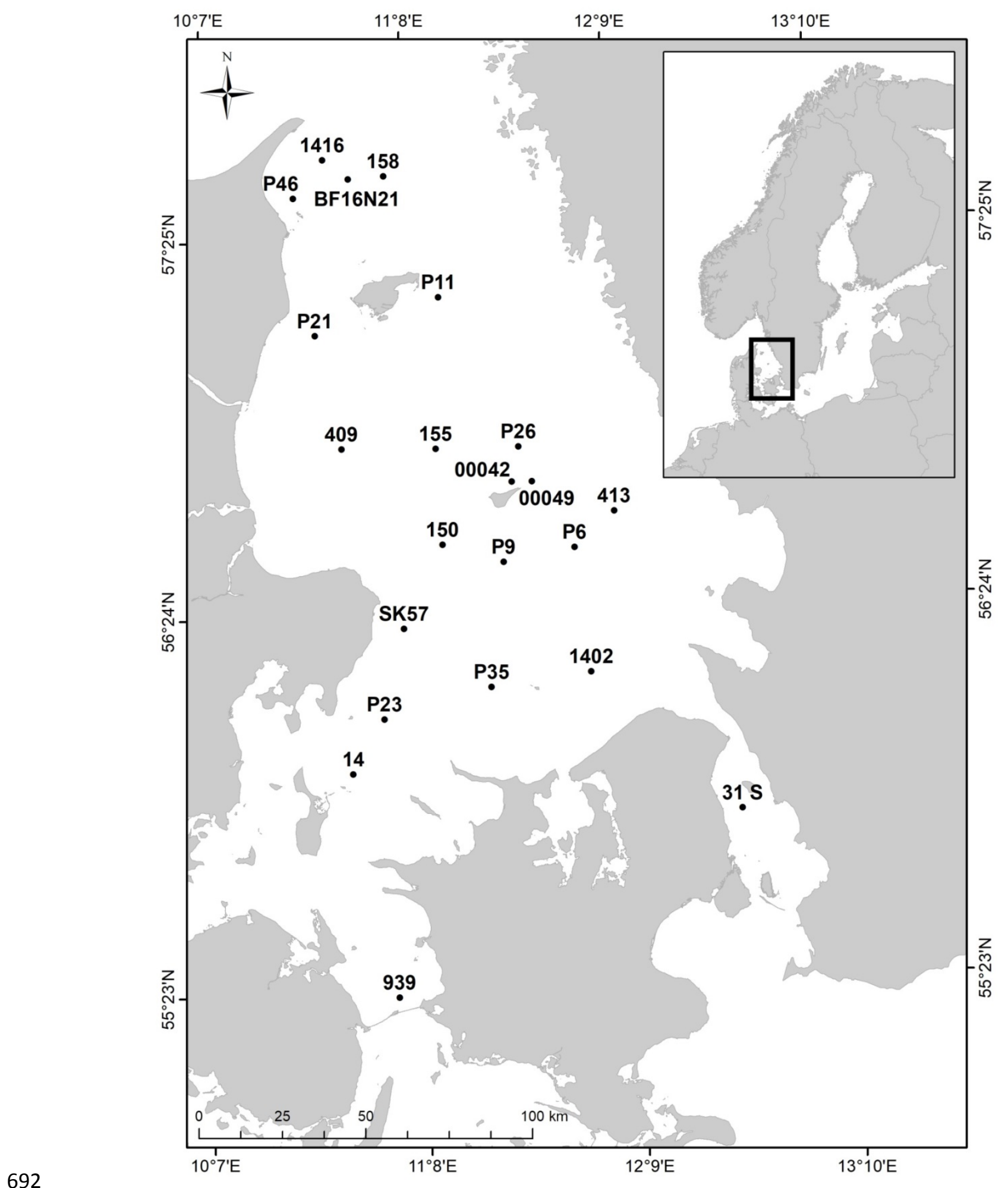

693 Figure 1. Map of sampling stations. 

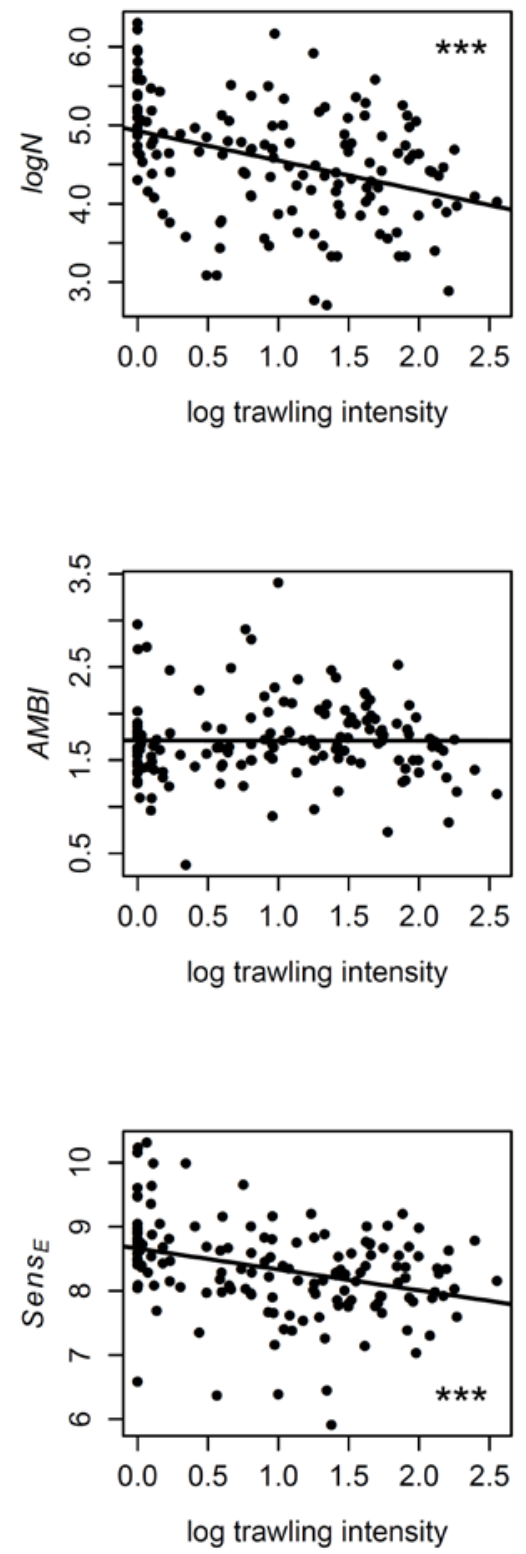

696 697 698 699 700
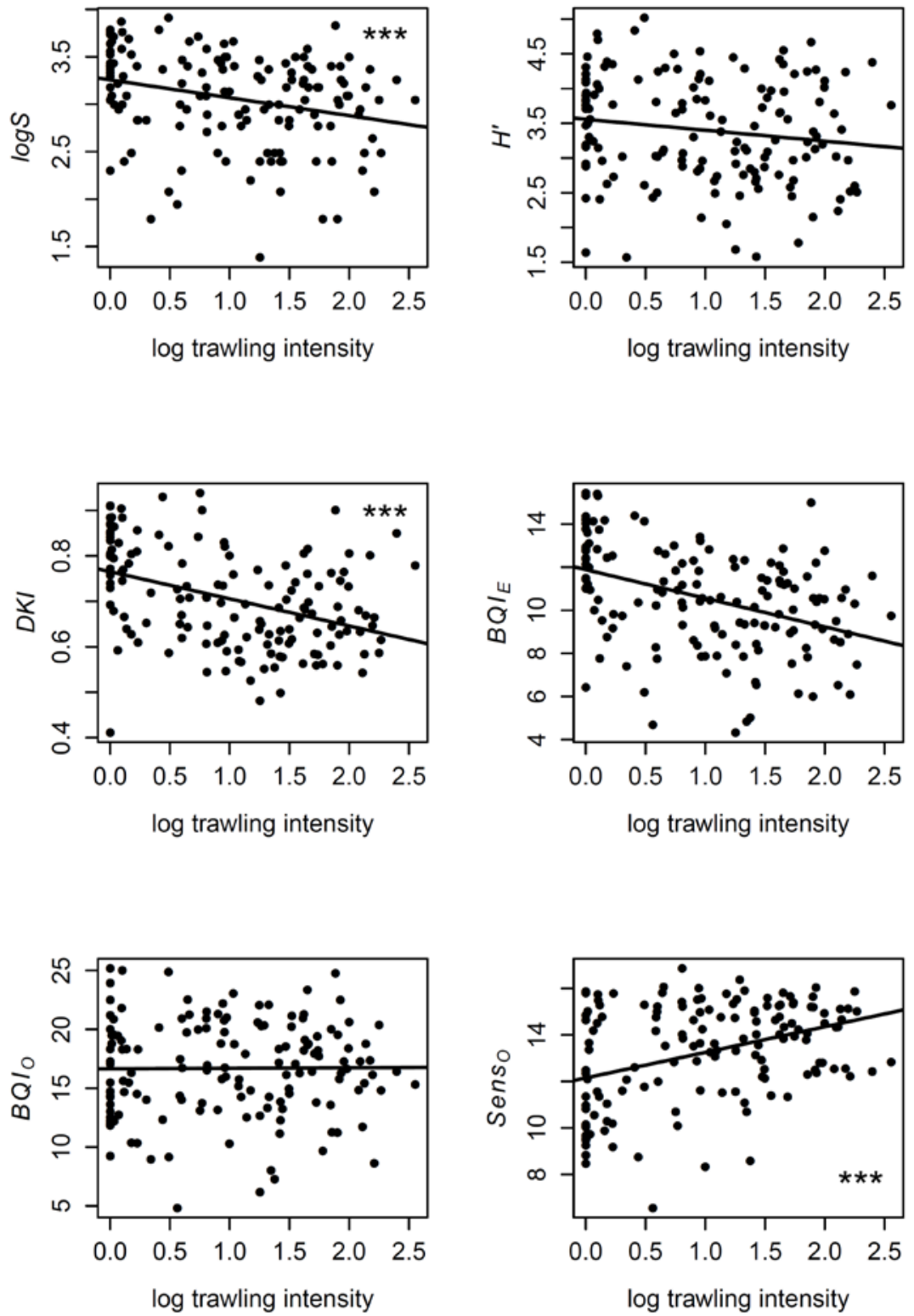

log trawling intensity

log trawling intensity

log trawling intensity

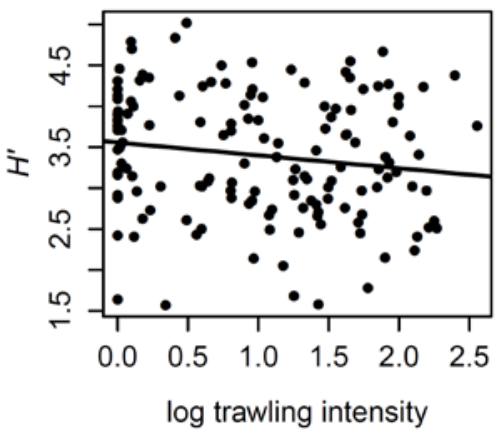




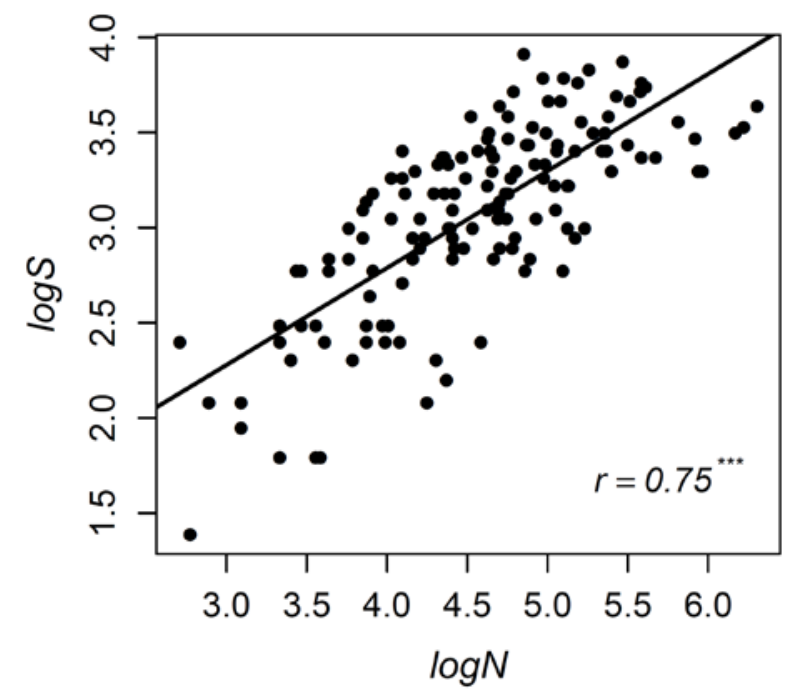

701

Figure 3. Linear relationship between log density and log species density.

703 

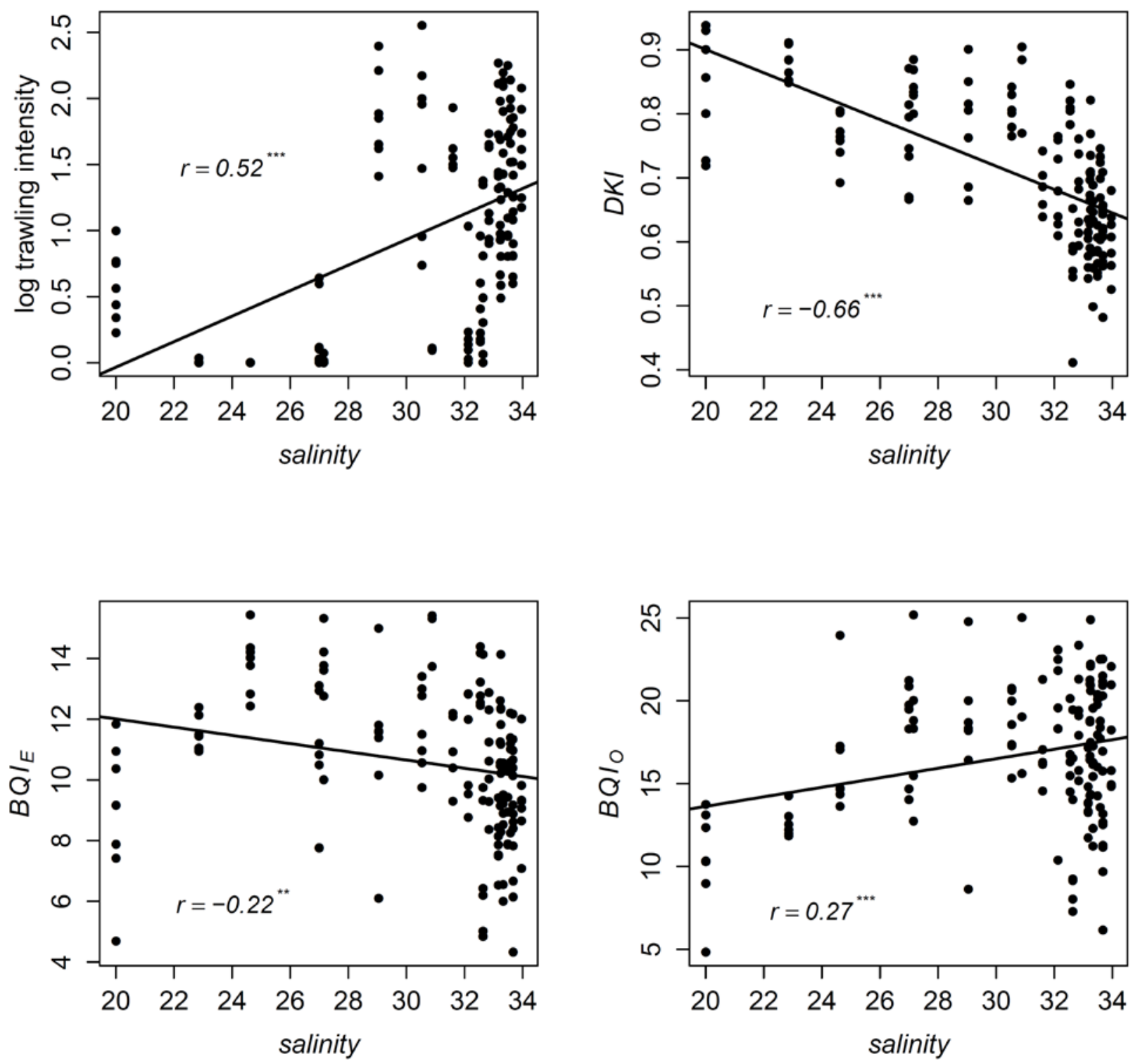

704

705 Figure 4. Log trawling intensity, $\mathrm{DKI}, \mathrm{BQI} \mathrm{I}_{\mathrm{E}}$ and $\mathrm{BQI}_{\mathrm{O}}$ versus salinity. 
a)

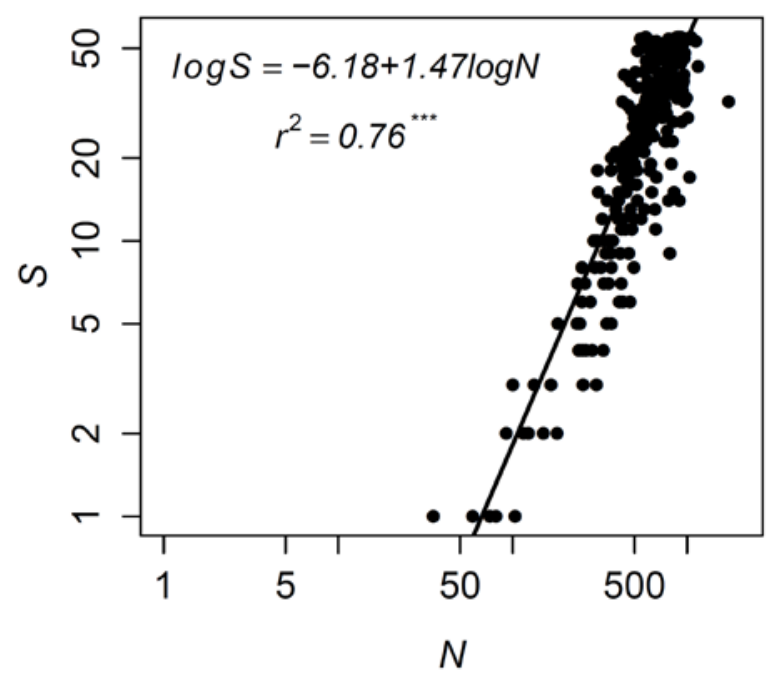

c)

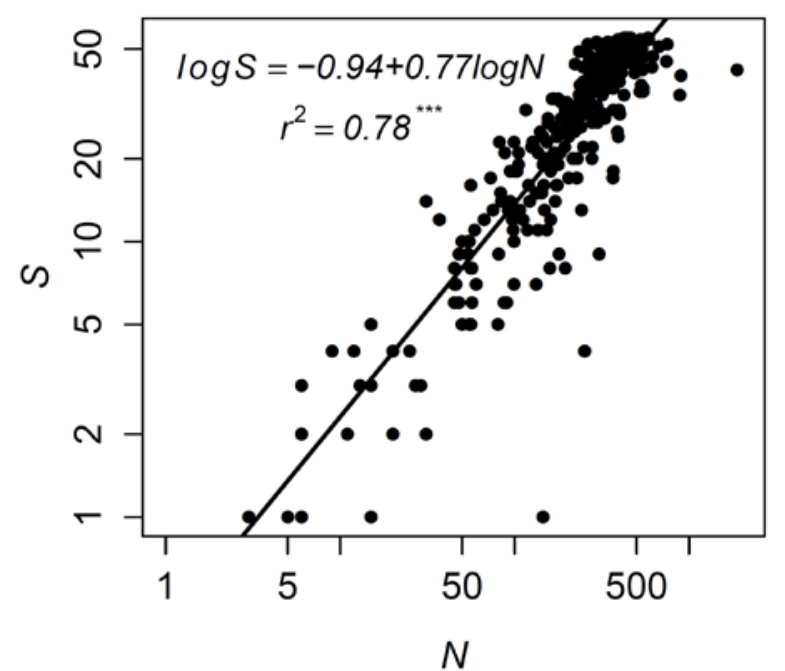

b)

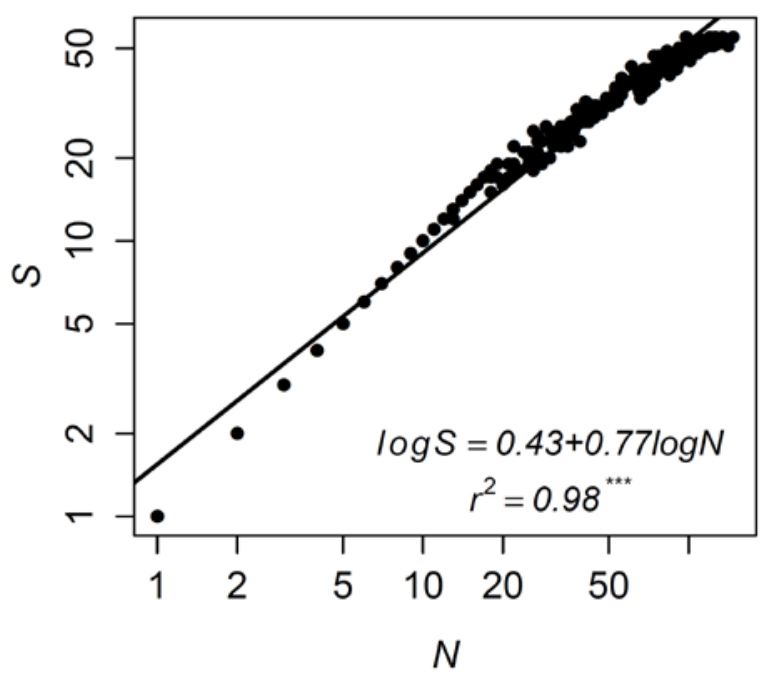

d)

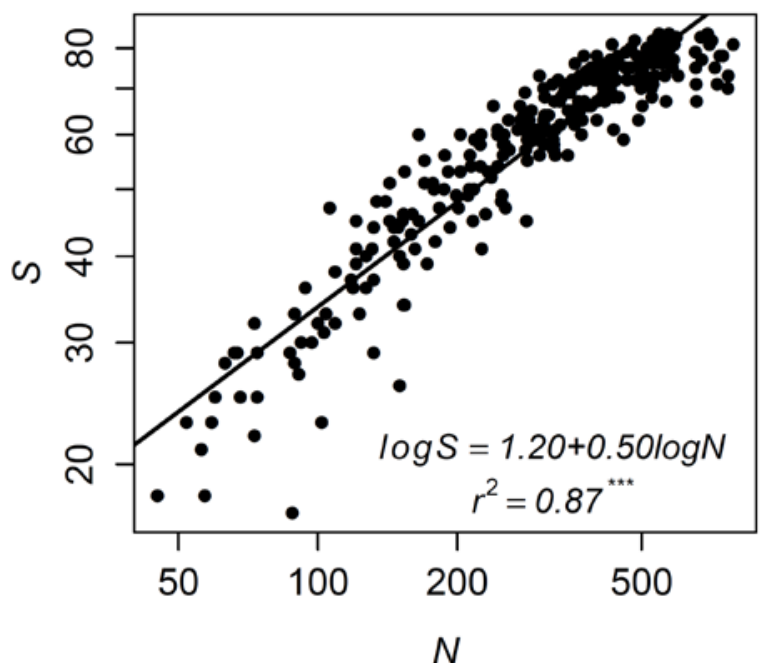

707

708 Figure 5. Simulated relationship between number of individuals and number of species.

709 Abundance of 100 species drawn at random from a lognormal distribution with a mean and 710 standard deviation of 1.3. Graphs show species abundance and number of species subject to a) 711 sequential removal of the least abundant species, b) sequential removal of the most abundant 712 species, c) random removal of species, and d) overall percentage reduction in abundance. 


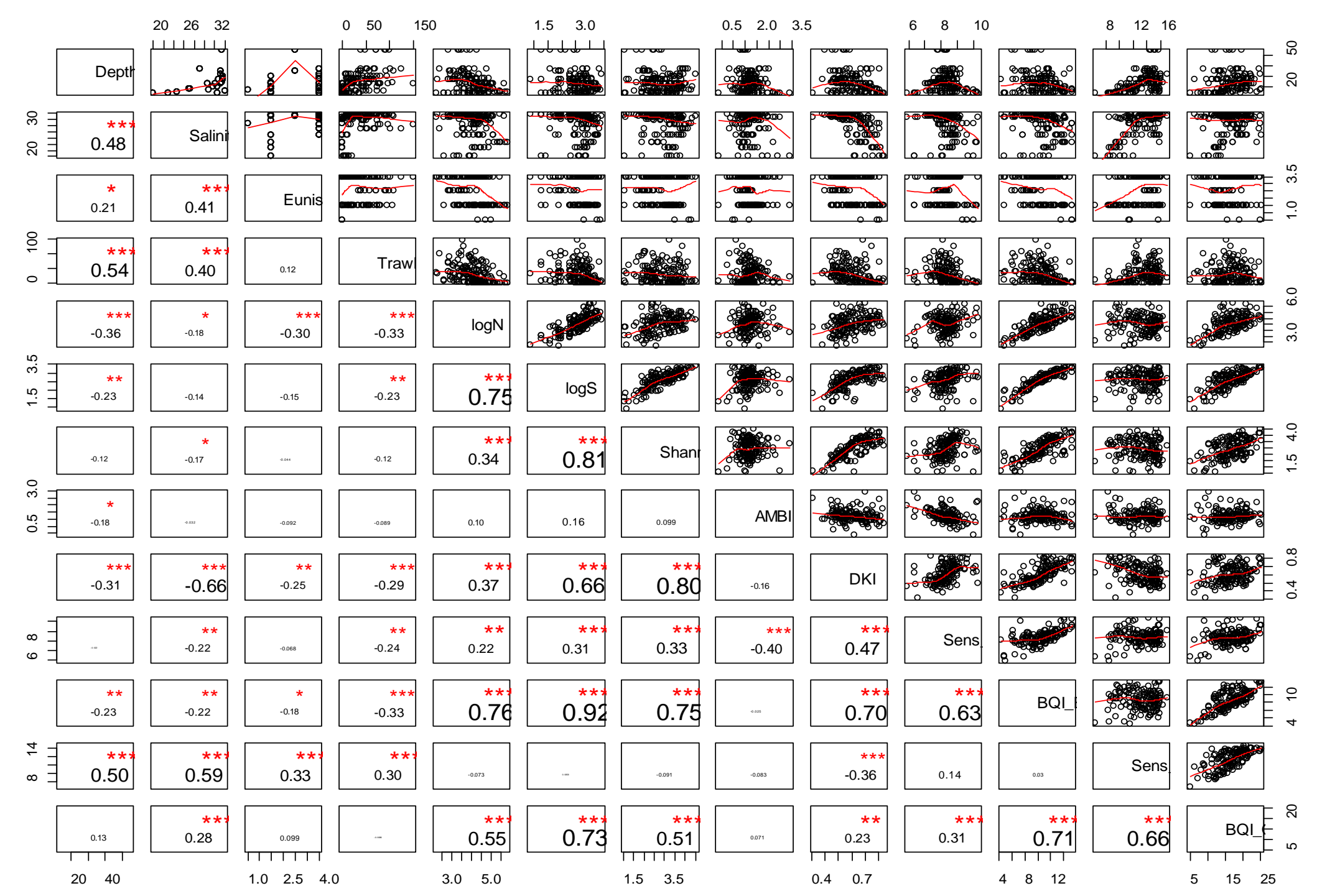

Figure S1. Pairs plot of dependent and independent variables with associated Pearson correlation coefficients. ${ }^{*}: \mathrm{P}<0.05$; **:P $<0.001 ; * * * \mathrm{P}<0.0001$ 